\section{ESTRATÉGIAS DIDÁTICAS NOS PROCESSOS DE ENSINO E DE APRENDIZAGEM EM MATEMÁTICA NO MUNDO DIGITAL VIRTUAL EM 3D OPEN SIM}

TEACHING STRATEGIES IN THE TEACHING AND LEARNING PROCESSES IN MATHEMATICS IN THE 3D DIGITAL VIRTUAL OPEN SIM WORLD

\section{ESTRATEGIAS DE ENSEÑANZA EN LOS PROCESOS DE ENSEÑANZA Y APRENDIZAJE EN MATEMÁTICAS EN EL MUNDO 3D DIGITAL VIRTUAL OPEN SIM}

Carloney Alves de Oliveira ${ }^{1}$

Luis Paulo Leopoldo Mercado ${ }^{2}$

\section{RESUMO}

Este artigo relata os resultados de uma pesquisa que investigou como se caracterizam os processos de ensino e de aprendizagem em Matemática no Mundo Digital Virtual em 3D (MDV3D) Open Sim com base em estratégias didáticas que se configuram para a sistematização do conhecimento geométrico entre professor e alunos, a partir das interfaces disponibilizadas no ambiente, tais como: sons, imagens, textos e vídeos. Analisa as contribuições e as potencialidades do Open Sim nos processos de ensino e de aprendizagem em Matemática, no Curso Imersão nos MDV3D - a Matemática em ação e movimento, envolvendo 20 alunos do Curso de Licenciatura em Matemática, presencial e a distância da Universidade Federal de Alagoas (UFAL). Os alunos apresentaram dificuldade de acesso ao ambiente pelo fato de nunca terem utilizado o Open Sim e as estratégias didáticas apresentadas de resolução de problemas na prática educativa, as possibilidades pedagógicas das tecnologias digitais nas aulas de Matemática, os jogos matemáticos e de raciocínio lógico propiciaram interação e estímulo na construção do conhecimento geométrico. 0 desejo por uma melhor prática na utilização do Open Sim pôde ser constatado, já que os alunos estavam à disposição para um acompanhamento sistemático e uma formação adequada, baseada no apoio, no diálogo e na colaboração. Os resultados apontam que o Open Sim permite a configuração de novas maneiras de aprender e ensinar Matemática pela interação e exploração do ambiente - na experimentação e na colaboração - no qual os sujeitos estão imersos, por meio de um avatar, proporcionando espaços para reflexões sobre o processo formativo de uma cultura emergente num espaço 3D.

\section{PALAVRAS-CHAVE}

MDV3D. Ensino da Matemática.

Estratégias Didáticas. Tecnologias Digitais. 


\section{ABSTRACT}

This article reports on the overall result of a research investigates how to characterize the processes of teaching and learning in Mathematics in Virtual Digital World 3D (MDV3D) Open Yes based on teaching strategies that are configured for the systematization of geometric knowledge between teacher and students from the interfaces available in the environment, such as sounds, images, texts and videos. Analyzes the contributions and potential of the Open Yes in the teaching and learning in mathematics, in the Course Immersion in MDV3D - mathematics in action and movement, involving 20 students of the Degree in Mathematics, classroom and distance. Students had difficulty in gaining access to the environment because they never used the Open Yes and teaching strategies presented in problem solving in educational practice, the pedagogical possibilities of digital technologies in math classes, mathematical games and logical reasoning propitiated interaction and encouraging the construction of geometric knowledge. The desire for a best practice in the use of Open Yes could be seen, as the students were on hand to systematic monitoring and appropriate training, based on the support, dialogue and collaboration. The results indicate that the Open Yes allows the configuration of new ways of learning and teaching mathematics by interaction and exploration of the environment - experimentation and collaboration - in which subjects are immersed, through an avatar, providing spaces for reflection on the formation process of an emerging culture in a 3D space.

\section{KEYWORDS}

MDV3D. Teaching of Mathematics. Didactic Strategies. Digital Technologies.

\section{RESUMEN}

Este artículo informa los resultados de una investigación que investigó cómo los procesos de enseñanza y aprendizaje en Matemáticas se caracterizan en el mundo virtual virtual en 3D (MDV3D) Open Sim basado en estrategias didácticas que están configuradas para la sistematización del conocimiento geométrico entre el maestro y estudiantes, desde las interfaces disponibles en el entorno, tales como: sonidos, imágenes, textos y videos. Analiza las contribuciones y potencialidades de Open Sim en los procesos de enseñanza y aprendizaje en Matemáticas, en el Curso de Inmersión en MDV3D - Matemáticas en acción y movimiento, involucrando a 20 estudiantes del Curso de Grado en Matemáticas, en persona y a distancia de la Universidad Federal de Alagoas (UFAL). Los estudiantes tuvieron dificultades para acceder al entorno porque nunca habían usado Open Sim y las estrategias didácticas presentadas para resolver problemas en la práctica educativa, las posibilidades pedagógicas de las tecnologías digitales en las clases de Matemáticas, los juegos matemáticos y el razonamiento lógico proporcionaron interacción. y estímulo en la construcción del conocimiento geométrico. Se podía ver el deseo de una mejor práctica en el uso de Open Sim, ya que los estudiantes estaban dis- 
ponibles para un monitoreo sistemático y capacitación adecuada, basada en el apoyo, el diálogo y la colaboración. Los resultados muestran que Open Sim permite la configuración de nuevas formas de aprender y enseñar Matemáticas a través de la interacción y exploración del entorno, en experimentación y colaboración, en el que los sujetos están inmersos, a través de un avatar, proporcionando espacios para reflexionar sobre el tema. Proceso formativo de una cultura emergente en un espacio 3D.

\section{PALABRAS CLAVE}

MDV3D. Enseñanza de las matemáticas. Estrategias didácticas. Tecnologías digitales

\section{INTRODUCÇÃO}

No contexto atual da cultura digital ${ }^{3}$, cada vez mais é necessário repensar as práticas pedagógicas e confrontá-las com o potencial das tecnologias digitais e de modo particular, os MDV3D, implicando competências e habilidades tecnológicas para compreender a essência da usabilidade, apropriação e planejamento, a fim de saber lidar com as possibilidades e sentidos que estes ambientes produzem e fazer escolhas de métodos e teorias que proporcionem uma reflexão e a motivação para a pesquisa como parte do processo de produção do conhecimento.

Pesquisas vêm sendo desenvolvidas com os MDV3D em diversas áreas, como design, engenharia, arquitetura na criação de projetos arquitetônicos, modelagem, planejamento e design urbano; na Física, permitem realizar simulações ou modelos físicos, criação de laboratórios experimentais; na Medicina e Biologia, aproveitam o poder de simulação do ambiente, como na criação de simulações de anatomia humana.

E, na Matemática, nos estudos sobre Geometria; na Geografia, tornando possível estudar mapas, por meio de coordenadas, latitude, longitude e altitude; na visita aos museus existentes nestes ambientes, podemos relacionar a História; os jogos e empresa, na criação de negócios empresariais; na simulação de diferentes formas de governança, incluem-se Administração, Marketing, Finanças e Contabilidade.

Os MDV3D têm provocado reflexões na educação por causa de sua capacidade de "ensinar". As possibilidades de implantação de novas técnicas de ensino são praticamente ilimitadas. Estudamos uma técnica que envolve o uso dessas tecnologias como mediação à prática pedagógica do professor

3 "No momento em que distintos artefatos tecnológicos entraram nos espaços educativos trazidos pelas mãos dos alunos ou pelo seu modo de pensar e agir inerente a um representante da geração digital evidenciou-se que as tecnologias digitais da informação e comunicação (TDIC) não mais ficariam confinadas a um espaço e tempo delimitado. Tais tecnologias passaram a fazer parte da cultura, tomando lugar nas práticas sociais e resignificando as relações educativas ainda que nem sempre estejam presentes fisicamente nas organizações educativas. Dentre os artefatos tecnológicos típicos da atual cultura digital, com os quais os alunos interagem mesmo fora dos espaços da escola, estão os jogos eletrônicos, que instigam a imersão numa estética visual da cultura digital; as ferramentas características da Web 2.0, como as mídias sociais apresentadas em diferentes interfaces; os dispositivos móveis, como celulares e computadores portáteis, que permitem o acesso aos ambientes virtuais em diferentes espaços e tempos, dentre outros”. (ALMEIDA; SILVA, 2011, p. 3). 
de Matemática em sala de aula, para que apresentem o seu uso na construção de conceitos matemáticos, relacionando o conteúdo trabalhado aplicável a tais recursos.

Por meio dos MDV3D são apresentadas estratégias didáticas ${ }^{4}$, com o objetivo de compreender como os alunos elaboram conceitos matemáticos a partir da utilização desses ambientes nas aulas de Matemática, a fim de que facilitem no cenário da aprendizagem matemática a compreensão dos alunos ao estudar e elaborar esses conceitos mediante tais conteúdos, criando materiais que possam favorecer estratégias pedagógicas de ensino e aprendizagem, como uma possibilidade de formação e superação das necessidades, das dificuldades de aprendizagem, bem como das carências e desafios atuais da educação.

Investigamos sobre como se caracterizam os processos de ensino e de aprendizagem em Matemática no MDV3D Open Sim a partir de estratégias didáticas que se configuram para a sistematização do conhecimento geométrico entre professor e alunos, tendo como protagonistas alunos do Curso de Licenciatura em Matemática presencial ou a distância da Universidade Federal de Alagoas (UFAL), visando a utilização desses recursos nas aulas de Matemática.

$\mathrm{O}$ artigo defende $\mathrm{o}$ argumento de que os processos de ensino e de aprendizagem em Matemática, vinculados para a sistematização do conhecimento geométrico, se desenvolvem na vivência com o Open Sim, no qual os sujeitos estão imersos, por meio de um avatar, a partir de estratégias didáticas propostas.

Organizamos o artigo, visando contextualizar melhor as razões pelas quais os MDV3D podem ter um lugar acentuado nas aulas de Matemática, em três seções: na próxima seção discutimos aspectos relativos sobre os MDV3D e suas concepções em contextos educacionais; a seguir argumentamos sobre as estratégias didáticas no ensino de Matemática nos MDV3D; logo em seguida, enfatizamos as questões metodológicas referentes a pesquisa desenvolvida que deu origem a este artigo; na sequência realizamos a apresentação e análise de dados, e por fim, concluímos então com algumas considerações acerca da experiência relatada.

\section{MDV3D E ESTRATÉ́GIAS DIDÁTICAS NO ENSINO DA MATEMÁTICA}

O MDV3D é definido como espaços digitais, de representação gráfica 3D, nos quais o sujeito é representado por meio de um avatar e que medeia a aprendizagem e o desenvolvimento de condições, estratégias e intervenções de aprendizagem num espaço virtual na internet, organizado de tal forma que propicie a construção de conceitos, por meio da interação de alunos e professores, também de recursos disponibilizados nestes ambientes.

A estrutura criada no Open Sim é composta de interfaces e estratégias programadas que respeitam o ritmo de cada usuário nesses ambientes para a construção da interatividade ${ }^{5}$ e da aprendizagem em relação a conceitos matemáticos, pois cada proposta de sala ambiente necessita compor esses espaços, no sentido de diferenciá-los em processos criativos de atualização.

4 Formas de intervenção na sala de aula que contribuem para que o aluno mobilize seus esquemas operatórios de pensamento e participe ativamente das experiências de aprendizagem, observando, lendo, escrevendo, experimentando, propondo hipóteses, solucionando problemas, comparando, classificando, ordenando, analisando e sintetizando. (MARTINS, 2009; HAYDT, 2006). 5 Lemos (1997) concebe interatividade como uma nova forma de interação técnica, de cunho eletrônico - digital, diferente da interação analógica, que caracteriza os media tradicionais. É a ação dialógica entre o homem e a técnica. 
Num MDV3D, cada avatar tem a liberdade para atuar e buscar seus interesses sem regras específicas, explorando e compreendendo estes ambientes, sendo capaz de perceber que a sua presença é parte integrante/atuante deste mundo, pois a imersão nestes ambientes não há limites de participações, interações com os objetos que neles se encontram e espaços do próprio ambiente. Segundo Behar e Maria (2013, p. 200), "os avatares podem criar, modificar e apagar objetos, interagir sobre diversas linguagens com os outros avatares, realizar explorações e passeios, trabalhar, namorar, entre diversas outras possibilidades" nos metaversos.

Além dessas características, podemos personalizar a aparência do avatar (fig. 1), editando diversas partes do corpo, utilizando modelos já existentes ou criando diferentes vestimentas e objetos para serem anexados, aumentando assim o grau de realismo.

Figura 1 - Personalização do avatar

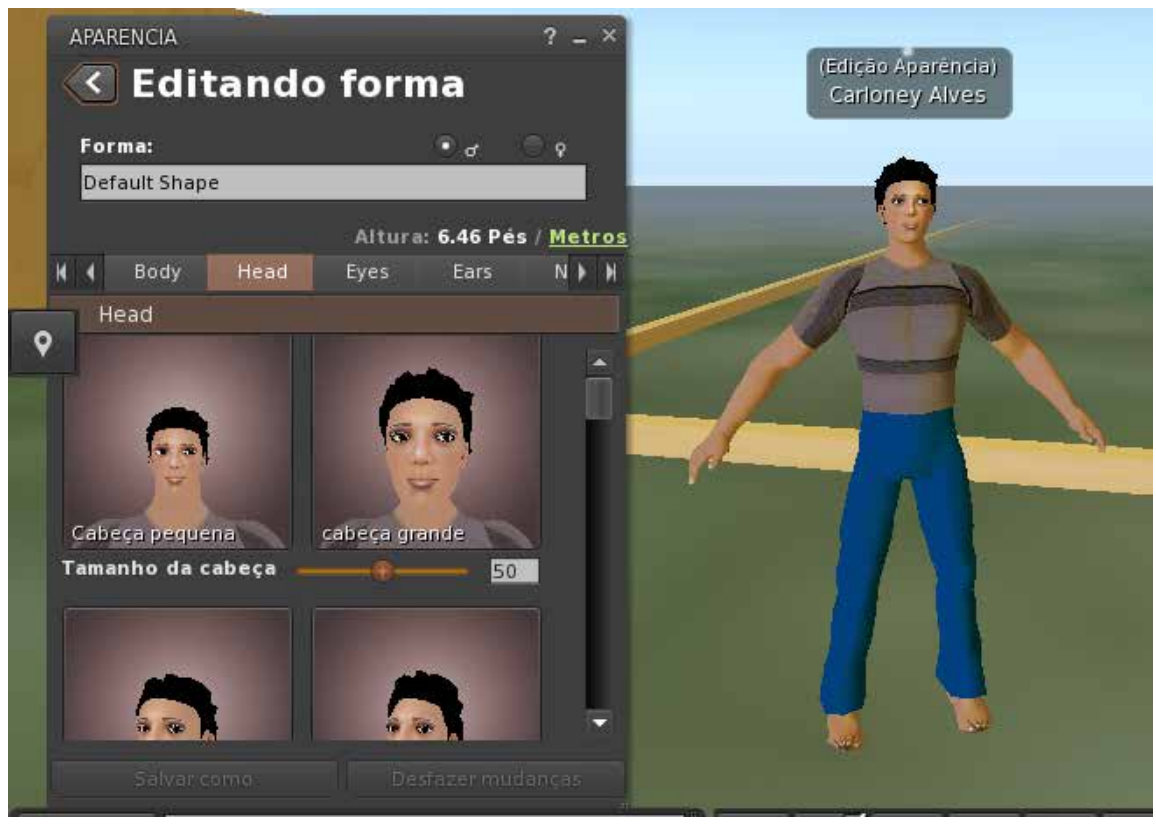

Fonte: Open Sim/UFAL (2015).

Para Backes (2011, p. 99), um MDV3D pode significar

[...] uma possibilidade de ampliação na configuração de espaços de convivência, utilizando não só os espaços de presença física, como também, os espaços de presença digital virtual. A presencialidade (física ou digital virtual), neste contexto, é definida pela participação e interação por meio da representação das suas ações no contexto onde se dá o viver e conviver dos seres humanos. 
Favorecer a interatividade e a aprendizagem por meio dos MDV3D é condição importante para a produção de significados e a garantia de que seus usuários agregaram valores na troca de experiências, na participação das atividades propostas e na construção do saber. Surge aí uma nova visão, sendo preciso incorporar elementos já existentes na web, elaborar atividades que utilizem as diferentes formas de comunicação (textual, oral, gráfica e gestual), podendo assim, professores e alunos vislumbrarem as potencialidades existentes num Espaço de Convivência Digital Virtual (ECODI), analisando, construindo, questionando e buscando soluções. De acordo com Schlemmer (2008, p. 24), um ECODI compreende diferentes tecnologias tais como

AVAs, MDV3Ds, tecnologias da web 2.0, agentes comunicativos (ACs - criados e programados para a interação), entre outros, que favoreçam diferentes formas de comunicação (textual, oral, gráfica e gestual); fluxo de comunicação e interação entre os sujeitos presentes nesse espaço; e fluxo de interação entre os sujeitos e o meio, ou seja, o próprio espaço tecnológico.

A partir desta concepção é preciso explorar a potencialidade destes espaços para que se estabeleçam laços de convivência que permitem atingir um nível de interação e participação com os avatares ali representados, nos quais os cenários se modificam em tempo real à medida que tais sujeitos agem e interagem com e no "mundo", com as informações nele apresentadas, problematizando-as e instigando-os no seu processo de aprender.

Para Schlemmer (2012, p. 83), um MDV3D pode

[...] reproduzir de forma semelhante ou fiel ao mundo físico ou pode ser uma criação diferenciada, desenvolvida a partir de representações espaciais imaginárias, simulando espaços não físicos para convivência digital virtual. Esses mundos podem ter leis próprias, nos quais podemos usar todo o poder da nossa invenção e criatividade, pois não estamos presos a regras físicas. Outra característica fundamental dos MDV3D é o fato de se caracterizarem como sistemas dinâmicos, ou seja, o ambiente se modifica em tempo real à medida que os seus usuários vão interagindo com ele.

0 acesso às informações proporcionado pelos MDV3D pode oferecer caminhos para essas novas propostas educacionais, mais adequadas aos novos tempos sociais, permitindo que as possibilidades para a autonomia na aprendizagem, oferecidas por estes mundos, facilitem o acesso de professores e alunos e concedam liberdade para escolher o tempo e o espaço que mais thes convêm para navegar. Como afirma Backes (2012, p. 191-192),

A representação da imersão no espaço de relação por meio de um avatar; o sentimento de presença e proximidade, que podem instigar a presencialidade e consequentemente a responsabilidade; as diferentes possibilidades de representação (gráfica, oral, textual e gestual) da percepção no processo de interação; as diversas formas de conversar e estabelecer diálogos; a oportunidade de exercer a autonomia 
(ação do avatar é que determina a presencialidade e a construção do mundo) e desenvolver a autoria (na medida em que é um espaço que permite diferentes formas de representar o conhecimento).

Os MDV3D apresentam interfaces que auxiliam o professor na organização dos conteúdos (atividades, material de apoio e leituras), que servem de ponte entre professores e alunos, viabilizando diálogo e a interação entre os envolvidos (mensagem e chat), publicando e organizando os trabalhos dos alunos, sejam individuais ou coletivos.

É possível, utilizando imagens, multimídias e textos, criar exibições dinâmicas e interativas para que os avatares possam interagir entre si, pois essas interfaces ajudam a estruturar, alterar, monitorar, atualizar todos os dados que formam um curso, permitindo uma flexibilidade entre usuários como essência fundamental para manter o diálogo contínuo, conservando o gerenciamento da aprendizagem, possibilitando aos professores e alunos, representados por avatares, navegar com facilidade pelo MDV3D, acompanhando as discussões, atendendo às solicitações e participando, quando percebem que é conveniente, já que estes mundos permitem uma prática pedagógica caracterizada, segundo Backes (2012, p. 195-196), pelo

[...] fazer autônomo, por meio do respeito mútuo, que consiste na ação do avatar em construir o mundo. Se o e-cidadão não constrói os MDV3D, nada existirá nesse espaço digital virtual; fazer responsável na construção dos MDV3D de maneira cooperativa, devido a sua complexidade para a realização dessa construção. Os e-cidadãos envolvendo-se na construção do todo para a apropriação do conhecimento sobre como se constrói, bem como a necessidade do outro para dar sentido e validade à construção metafórica; construção de um projeto comum, entre e-cidadãos de diferentes lugares (físicos), para a realização dos MDV3D; o comum e o diferente estão relacionados dialeticamente; projeto comum, que se constrói na dinâmica de relações do viver e conviver nos MDV3D.

O que facilita e incentiva a mistura e o uso de diferentes linguagens, da oralidade (vídeos) à escrita (mensagens e chat) são as interfaces disponíveis no MDV3D, inerentes a todo o processo. Schlemmer (2012, p. 81) afirma que os “MDV3D podem ser compreendidos como um híbrido entre ambientes virtuais de aprendizagem, jogos, comunicadores instantâneos, mídias sociais, ou seja, os MDV3D possuem elementos de diferentes tecnologias digitais virtuais". Essas características permitem que usuários distribuídos geograficamente possam acessar e interagir em tempos e espaços que privilegiem seus interesses.

Compreender como as diferentes estratégias didáticas podem se desenvolver a partir de um MDV3D no contexto da educação e, de modo particular, no ensino de Matemática, possibilita entender de maneira integrada que é possível mediar o processo de ensino e de aprendizagem por meio de recursos didáticos disponibilizados nestes mundos, por meio da comunicação síncrona e assíncrona e na produção de atividades individuais ou em grupo. 
Considera-se o desenvolvimento interativo dos MDV3D pela capacidade de oferecer aos avatares um ambiente de compartilhamento de informações, reflexões, estabelecimento de relações, pesquisa, elaboração de projetos e aventuras. Para Pereira (2007, p. 86), tais mundos têm despertado interesse pelo fato de que

[...] são movidos a aventuras, descobertas e estão conectados com a maioria das mídias e tecnologias contemporâneas. Os jovens buscam estratégias motivadoras para comunicar, expressar e interagir com o meio. Algumas estratégias voltadas para o ensino, são recomendadas nesta idade: trabalhar com jogos mentais, criar expectativas, trabalhar com incertezas, e surpresas.

No Open Sim, é possível disponibilizar um espaço hipertextual que dá acesso a "diferentes caminhos, teias e redes e trilhas, numa textualidade inacabada, de possibilidades nunca fechadas" (SILVA, 2008, p. 80).

Trabalhar numa linguaguem hipertextual nos MDV3D é criar condições para a imersão dos avatares a partir de propostas inovadoras que favoreçam a interação, reflexão, compartilhamento, colaboração, mediação pedagógica, prática e teoria que estimulem a curiosidade, a criatividade na construção do conhecimento, de ideias que fomentarão a base comunicativa na rede e não serem somente consumidores passivos da informação.

As potencialidades dos MDV3D nas aulas de Matemática permitem que os professores possam problematizar, investigar, comparar, indagar e dinamizar os espaços dentro e fora da escola, a partir desses ambientes, servindo como base para a adoção de medidas que visem superar as dificuldades e avançar em seu desenvolvimento da prática pedagógica, da mesma forma que se torna importante repensar os cursos de formação inicial e continuada para professores.

Conforme Valente (2002, p. 21), “o professor precisa compreender as ideias do aprendiz e sobre como atuar no processo de construção de conhecimento para intervir apropriadamente na situação, de modo a auxiliá-lo neste processo".

Mediante a potencialidade que o Open Sim tem para explorar encontros, palestras ou apresentações entre os avatares, é possível dialogar e interagir sobre a temática escolhida, adaptando o ambiente às necessidades do grupo, tendo como objeto de reflexão a importância dos MDV3D em aulas de Matemática e suas contribuições na formação inicial e continuada do professor.

\section{CAMINHO METODOLÓGICO: O PENSAR/FAZER DA INVESTIGAÇÃO}

A experiência se deu no Open Sim (FIGURA 2), desenvolvido para a realização da pesquisa, por meio de um Curso de Extensão, durante três meses, com encontros presenciais e on-line, realizado com 20 alunos do Curso de Licenciatura em Matemática, selecionados na modalidade presencial e a distância, constituindo num espaço significativo que possibilita leituras, pesquisas, realização de atividades, desafios, construções e diálogos sobre as temáticas propostas ao longo do curso. 
Figura 2 - Tela inicial do MDV3D do Centro de Educação da UFAL

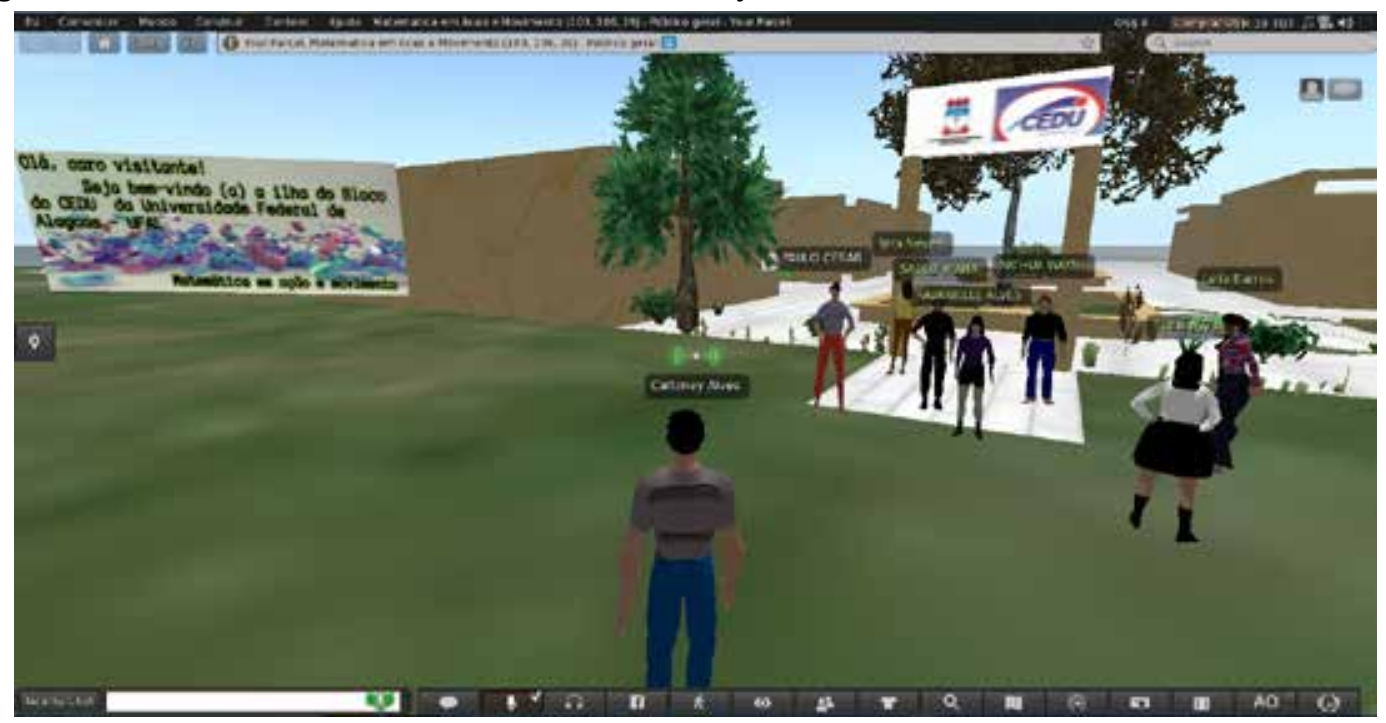

Fonte: Open Sim/UFAL (2015)

Foram realizados encontros presenciais e on-line, assim organizados: quatro horas no primeiro encontro presencial para apresentação, orientação e discussão da proposta do curso; quatro no segundo encontro presencial, com diálogos a partir de leituras propostas sobre MDV3D, ECODI, características, contribuições e potencialidades para o contexto educacional; num próximo encontro presencial de oito horas foi trabalhada a ambientação no Open Sim, sendo desenvolvidas atividades para a exploração dos recursos disponíveis no ambiente e produção de objetos que estabelecessem uma relação prática com o ensino de Matemática e objetos do mundo real na experimentoteca, espaço reservado para que os sujeitos utilizem da sua criatividade e possam explorar as ferramentas de construção e suas possibilidades no Open Sim.

Os demais encontros foram totalmente on-line totalizando 40 horas para navegabilidade no ambiente, interação com os sujeitos envolvidos no curso por meio de discussões a partir do chat e áudio disponível no Open Sim, produções de espaços que tornem as aulas de Matemática dinâmicas, interativas e atrativas, entre outras propostas. Ao final do curso foi realizado um encontro presencial de quatro horas para avaliação geral das atividades desenvolvidas pelo grupo no ambiente e sugestões para melhores práticas.

A pesquisa é de cunho qualitativo e os dados foram coletados por meio da imersão e interação entre os pesquisadores e os participantes do curso de extensão. A interação entre pesquisador e pesquisado se deu por meio de avatar no Open Sim, possibilitada no viver e conviver entre os sujeitos, o que permitiu o "face a face", o "olho no olho" entre avatares, ou seja, o meu eu digital virtual (minha identidade digital virtual) pode "ver" o outro (a identidade digital virtual de outros sujeitos) e o outro (avatar) pode me "ver" (o meu avatar) (SCHLEMMER, 2012). 
No espaço destinado ao curso foram organizadas atividades de ambientação, tais como modificações na aparência dos avatares, exploração do chat e o uso de voz, permitindo uma interação entre eles, construção de objetos 3D e propostas de aulas de Matemática por meio desses ambientes, considerando o contexto em que cada um está situado, desenvolvendo ações como andar, voar, correr, sentar, dentre outras, bem como o processo de ensino e de aprendizagem, por imagens, textos, sons e vídeos, para que outras ações pudessem ser desenvolvidas no ambiente, possibilitando aos avatares se envolver, experienciar e reagir a informações contextualizadas ao ensino de Matemática, permitindo explorar as potencialidades e as contribuições destes ambientes.

A coleta de dados (QUADRO 1) permitiu analisar as ações dos sujeitos mediante os desafios, nas interações, no envolvimento para o desenvolvimento do curso, como relevantes para a compreensão, a descrição das situações em que se dão as práticas de ensino em Matemática nesses ambientes, já que se constituem situações novas e inovadoras, que exigem certo grau de liberdade e engajamento do grupo, para que as técnicas e os instrumentos da pesquisa sejam adequados à problemática enunciada.

Quadro 1 - Síntese da coleta de dados

\begin{tabular}{|c|c|}
\hline Técnica e Finalidade & Registro \\
\hline $\begin{array}{l}\text { Observação Participante do grupo } \\
\text { no Open Sim } \\
\text { Descrever sobre o ambiente } \\
\text { escolhido para o desenvolvimento } \\
\text { da pesquisa. } \\
\text { Observar como os sujeitos utilizaram } \\
\text { e se apropriaram dos recursos } \\
\text { disponiveis no ambiente. } \\
\text { Descrever ações dos avatares em } \\
\text { situações de interação. } \\
\text { Registrar presenças e ausências } \\
\text { dos avatares nos encontros online } \\
\text { programados. } \\
\text { Observar o grupo de avatares no } \\
\text { desenvolvimento das atividades } \\
\text { propostas. } \\
\text { Registrar dificuldades de interação } \\
\text { e resolução das situações } \\
\text { apresentadas. } \\
\text { Descrever os sentimentos e } \\
\text { expressões de ideias de cada avatar } \\
\text { referente ao ambiente. }\end{array}$ & $\begin{array}{l}\text { O ambiente escolhido para o desenvolvimento da pesquisa } \\
\text { foi o Open Sim, um ambiente de código aberto que permite } \\
\text { personalizar e simular em tempo real situações do mundo } \\
\text { físico. } \\
\text { Os sujeitos tiveram um momento de ambientação no Open Sim } \\
\text { e, a partir daí, não foi difícil utilizar os recursos disponíveis, já } \\
\text { que foram orientados anteriormente. } \\
\text { Os avatares ao serem desafiados com atividades propostas } \\
\text { no ambiente e discussões sobre alguma temática sugerida, } \\
\text { trabalharam individual ou em grupo realizando o que era } \\
\text { sugerido. } \\
\text { Inicialmente os avatares tiveram dificuldades de acesso ao } \\
\text { ambiente, já que teriam de baixar o visualizador e a internet } \\
\text { na universidade não colaborou, impedindo o acesso, mas } \\
\text { buscamos alternativas para que a internet fosse roteada através } \\
\text { dos celulares dos sujeitos envolvidos. } \\
\text { Mesmo acessando o ambiente após início dos encontros online, } \\
\text { os avatares não deixaram de participar dos encontros. } \\
\text { Sentimentos de satisfação e adesão ao curso de extensão, } \\
\text { foram registrados no momento da avaliação pessoal, pois } \\
\text { para a formação dos sujeitos envolvidos, este foi um momento } \\
\text { exclusivo que nunca tiveram ao longo do curso de Licenciatura } \\
\text { em Matemática. }\end{array}$ \\
\hline
\end{tabular}




\section{Entrevista online/Levantamento de dados online}

Verificar se os sujeitos envolvidos na pesquisa já participaram de algum curso que envolvesse um MDV3D. Identificar o que sabem sobre os MDV3D.

Dialogar com os sujeitos se o Open Sim é um ambiente de fácil navegabilidade.

Verificar quais foram as dificuldades encontradas ao participar deste curso através do Open Sim.

Compreender quais foram as estratégias utilizadas na resolução das atividades

propostas ao longo do curso e a que atribui esse fato.

Solicitar aos sujeitos envolvidos sugestões para melhor utilização do Open Sim ao longo do curso.

Registrar as avaliações de cada avatar referentes à sua participação, interação e desenvolvimento das atividades propostas durante 0 curso
Verificar se os sujeitos envolvidos na pesquisa já participaram de algum curso que envolvesse um MDV3D.

Identificar o que sabem sobre os MDV3D.

A informação de que é um ambiente de fácil navegabilidade foi confirmada quando diziam "de navegação boa e que disponibiliza recursos que podem ser utilizados nas nossas aulas".

Os alunos tiveram dificuldade de acesso ao ambiente devido à internet da universidade não permitir a navegação.

Revelaram que a dificuldade de utilização não estava nas suas interfaces e sim na compreensão de como seriam disponibilizados os recursos do MDV3D para as aulas de Matemática e como poderiam ser propostos.

Os 20 sujeitos inscritos nunca participaram de algum curso que envolvesse a temática MDV3D.

Já ouviram falar sobre MDV3D, mas nunca tiveram a sensação de imersão.

A informação de que é um ambiente de fácil navegabilidade foi confirmada quando diziam "de navegação boa e que disponibiliza recursos que podem ser utilizados nas nossas aulas".

Os alunos tiveram dificuldade de acesso ao ambiente devido à internet da universidade não permitir a navegação. Revelaram que a dificuldade de utilização não estava nas suas interfaces e sim na compreensão de como seriam disponibilizados os recursos do MDV3D para as aulas de Matemática e como poderiam ser propostos. Os alunos apresentaram suas estratégias de resolução através de desenhos, registros textuais, escrita em chate elaboração de objetos em 3D, sendo modelados com os recursos disponíveis no Open Sim. Como sugestões solicitaram que mais cursos utilizando esses ambientes na sua formação fossem propostos e contextualizados de acordo a necessidade de cada grupo e que os professores da universidade fossem convidados a participar também.

Ao final do curso, os alunos através do chat disponibilizado no ambiente, registraram suas avaliações, contemplando os aspectos positivos e negativos que foram destaque para o aperfeiçoamento de cursos futuros, tais como: problemas de conexão, internet bloqueava a entrada ao ambiente, excelente participação dos sujeitos envolvidos, dedicação e comprometimento dos colegas e professores ministrantes 


\section{Diário de campo virtual/notas de campo reflexivas}

Registrar de cada avatar itens como assiduidade, disponibilidade, pontualidade e interação com o contexto proposto, a partir da dimensão comportamental.

Diagnosticar se os avatares demonstraram interesse e dedicação em aprofundar os conhecimentos relativos ao ambiente proposto.

Registrar de cada avatar o seu desenvolvimento oral e escrito na realização das atividades propostas e seu de raciocínio lógico.

Observar se cada avatar exercita uma postura crítica e investigativa ao longo do curso.

\section{Registro visual}

Capturar informações e fatos que estavam acontecendo no ambiente durante o curso, seja através do print screen da tela ou através do ícone da máquina de fotografar.

existente no ambiente, registrando imagens importantes e significativas para a pesquisa.

Armazenar num banco de dados imagens capturadas para que possam ser analisadas numa perspectiva qualitativa.
Todos os avatares demonstraram interesse, disponibilidade e assiduidade, porém, pontualidade, alguns avatares não contemplaram, mas mesmo assim, sempre que atrasados nos encontros online, não deixaram de participar e de se envolver nas atividades propostas e nas discussões temáticas.

Interesse e dedicação não faltaram em todo o grupo. Independentemente de os trabalhos serem realizados individual ou coletivamente, verificou-se o envolvimento de todos, ajudando-se mutuamente.

Sempre que algum avatar precisou de ajuda, o outro avatar registrava a sua preocupação, indo ao seu encontro para orientação.

Os avatares quando convidados a registrar o desenvolvimento das atividades e discussões temáticas através da oralidade ou da escrita, tiveram o compromisso de participar e apresentar o que era necessário ou até mesmo sugerir um maior envolvimento.

Cada avatar manteve uma postura crítica e investigativa ao longo do curso, utilizando e se apropriando dos recursos disponíveis no ambiente e da sua navegabilidade.

Imagens dos fatos foram capturadas durante o curso, tai como: realização de atividades propostas, reuniões temáticas entre os avatares, diálogo no chat sobre questões propostas, construção dos objetos em 3D, avatares reunidos para apresentação do banner, orientação sobre o Open Sim no encontro sobre ambientação, encontro para discussão sobre Geometria no ensino fundamental, avatares disponibilizando suas estratégias de resolução, encontro de avaliação da trajetória de cada avatar durante o curso.

Fonte: Os autores (2015). 
Os dados coletados foram agrupados nas seguintes categorias: (1) articulação da teoria pedagógica e prática docente no ensino de Matemática; (2) contribuições e os impactos dessa formação no Open Sim para o Curso de Licenciatura em Matemática da Ufal; (3) utilização do Open Sim na formação do professor; (4) navegabilidade dos alunos no Open Sim; (5) dificuldades de utilização do Open Sim; (6) estratégias didáticas que possibilitam melhores práticas no Open Sim.

Os dados foram avaliados a partir da Análise Textual Discursiva (ATD), permitindo a verificação de ocorrências relativas aos objetivos propostos, fazendo a articulação entre o contexto vivenciado e os referenciais adotados, pois, segundo Moraes e Galiazzi (2013, p. 16), “a análise textual caracteriza-se a partir de um conjunto de documentos denominado 'corpus'”. Este representa as informações da pesquisa e para a obtenção de resultados válidos e confiáveis requer uma seleção e delimitação rigorosa”.

\section{OPEN SIMCOMO AMBIENTE DE ENSINO E DE APRENDIZAGEM NAS AULAS DE MATEMÁTICA}

Ao considerar a importância dos MDV3D na formação do professor, suas metodologias, práticas e mediações pedagógicas, interfaces, contribuições e potencialidades para os processos de ensino e de aprendizagem em Matemática, a partir de estratégias didáticas que possibilitem melhores práticas por meio destes ambientes, analisamos o desenvolvimento do curso de extensão Imersão nos MDV3D: matemática em ação e movimento realizado no Open Sim, entre setembro e dezembro de 2014, para melhor compreender as informações e a construção de ideias significativas, a partir dos desafios que emergiram durante o processo de parte dos alunos inscritos, considerando que o ambiente e a experiência vivida por eles constituíam situações novas, que exigiam do grupo, participação, engajamento, espírito investigativo, autonomia, persistência e ânimo.

As estratégias didáticas propostas nestes ambientes apontaram caminhos para melhor promover a autonomia, a interatividade e a colaboração entre os usuários. Neste sentido, para encontrar respostas à problemática apresentada, serviram de base para as análises as respostas das entrevistas on-line com os alunos, as observações no MDV3D elaborado para a realização da pesquisa, a partir de cada encontro planejado e desenvolvido durante o curso, diálogo em chats, entrevistas on-line e imagens do ambiente. A transcrição da fala e escrita dos sujeitos ocorreu na íntegra e buscamos preservar a identidade dos sujeitos optando pelo uso de um código ( $A=$ avatar).

A partir das observações no Open Sime, mediante entrevistas com os alunos do curso de extensão investigado, constatamos que já ouviram falar em MDV3D, sabem o básico sobre estes espaços e que nunca o utilizaram. Na busca de orientação, foram em busca de textos, vídeos e exemplos que contribuíssem para a sua formação, articulando a teoria pedagógica e a prática docente no ensino de

Matemática, ampliação de conceitos e conhecimento sobre os conteúdos propostos, compreendendo um MDV3D como um ambiente "autoexplicativo e que aprendi a utilizar para acompanhar o curso e interagir com os colegas e professor (A1)”.

Ainda, "de navegação boa e que tem bons tutoriais, inicialmente aprendi apenas o básico. Primeira vez, que vejo esse ambiente (A12)", "que, dependendo do conhecimento que se tenha, ele é de fácil navegabilidade, sei apenas o básico deste programa (A3)", "posso dizer que é um programa de fonte 
aberta voltada para a educação (A15)" e "uma plataforma que disponibiliza várias ferramentas que podem ser utilizadas nas nossas aulas, principalmente, de Matemática (A20)".

Apesar da falta de conhecimento sobre Open Sim e suas interfaces, percebemos que A1 e A20 compreendem a importância do ambiente para as aulas de Matemática e têm desejo de participar, comunicar, colaborar, até mesmo se apoiaram nas trocas de mensagens rotineiras, dentro do ambiente, buscando informações propostas pelo professor, o que propiciou a liberdade de trilhar caminhos não lineares em busca da ampliação de conhecimentos.

À proporção que se reflete sobre a postura e a prática de cada aluno no curso, o avatar A20 percebe o aperfeiçoamento da utilização das interfaces e a compreensão da dinâmica de utilização da proposta pedagógica de cada atividade apresentada:

0 avanço que tive ao longo do curso, minha autonomia, utilização das ferramentas e compreensão da arquitetura do ambiente, sendo mais maduro para compreender toda a dinâmica de usabilidade do Open Sim, percebi o grande fascínio e estímulo deste espaço para a nossa formação. A cada encontro uma expectativa de como seria e o que faríamos durante o curso (A20).

Com esse propósito disponibilizamos, ao longo dos espaços criados no Open Sim, várias atividades matemáticas que foram codificadas por meio de um QR CODE FIGURA 3), com o objetivo de levar o aluno a resolver problemas matemáticos, conhecer e avançar aos ambientes solicitados após encontrar a solução, possibilitando intervenções e questionamentos para gerar novas discussões de conteúdos matemáticos, fortalecendo as diferentes formas de mediar o conhecimento a partir de um MDV3D, desenvolvendo a autonomia e a criatividade, competências dificilmente incentivadas em modelos tradicionais de educação, sejam eles presenciais ou não.

Figura 3 - $1^{\text {a }}$ Atividade matemática em QR Code e Resolução de um desafio via chat
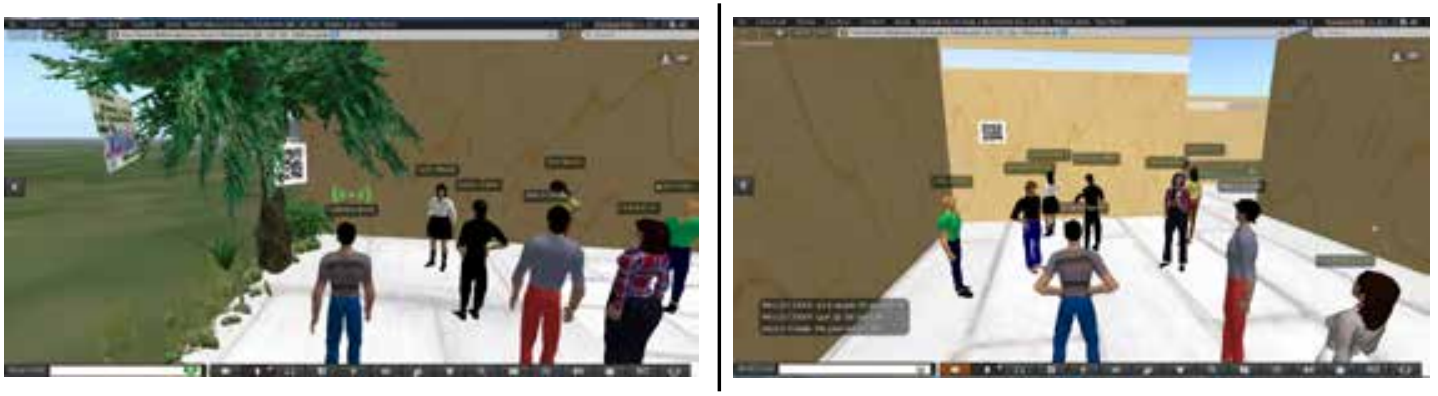

Fonte: Open Sim/UFAL (2015). 
Com o QR Code apresentado, os sujeitos foram convidados a utilizar qualquer aplicativo que fizesse a leitura do código para verificar qual seria a situação proposta, a fim de sistematizar o conteúdo e dinamizar o que estava sendo trabalhado, ampliando a visão do grupo nas mais diferentes estratégias didáticas que podem ser exploradas no Open Sim, para que alternativas de ensino sejam modeladas num espaço que incentive a reflexão, a cooperação e a construção de conceito.

Alguns avatares, compreendendo o problema proposto, começaram a utilizar também o chat para apresentar sua resolução, tomando o diálogo e a cooperação como formas de aprendizagem, respeitando o tempo e o espaço de cada um, de dizer ou silenciar para escutar o outro, apropriando-se da interface na perspectiva de considerar o sujeito como ativo e consciente dos processos de construção do seu próprio conhecimento, à luz das propostas de atividades.

À medida que o curso foi evoluindo mediante o conjunto de estratégias para incentivar o aluno a estudar, pesquisar de modo independente e, ao mesmo tempo, estimular a aprendizagem coletiva, todo o grupo foi buscando soluções para os problemas apresentados no início do curso.

Percebeu-se que, estimulando a interação e a integração do grupo, os alunos buscaram mediar o conhecimento, esclarecendo possíveis dúvidas referentes ao conteúdo trabalhado no curso, nas resoluções dos problemas e orientação durante os encontros planejados no ambiente, sejam eles presenciais ou a distância.

A partir das observações no Open Sim em cada encontro realizado, o ritmo ativo dos alunos levou a uma maior participação e dinâmica de trabalho em cada atividade proposta, detectando, diagnosticando, estimulando, dando uma visão global do tema estudado, situando o assunto aprendido no conjunto das situações-problema, as relações do estudo com interesses particulares e profissionais de cada aluno, motivando-os a superar suas dificuldades e a organizar seu tempo para estudo e participação no curso, compreendendo suas contribuições e os impactos da formação nos MDV3D para o Curso de Matemática.

Nesses espaços, os alunos precisavam ser acompanhados, para que não se sentissem sozinhos, sendo conduzidos pelo professor, explorando os recursos do ambiente, facilitando, de forma participativa, reflexiva e dinâmica, a sua aprendizagem.

Ao possibilitar interações, os avatares A1, A20 e A7 assumiram o seu papel ativo: conduzir tal situação, na tentativa de refletir diante de situações-problema em cursos nesse formato dentro de um MDV3D, facilitando a assiduidade do aluno ao curso e a condução devida para realização das atividades, em que se buscaram contribuições para a discussão, desenvolvimento e reconhecimento de alternativas do contexto educacional, como revelam as falas dos sujeitos da pesquisa:

"Gostei do ambiente e das atividades propostas nele, consigo expor os pontos positivos e negativos, com comentários da realidade vivida, em relação alguns momentos de ausência dos colegas e a falta de leitura dos materiais expostos" (A1), "Muito importante esse curso, pois precisamos de uma formação inicial e continuada através desses ambientes para que possamos refletir sobre a nossa prática pedagógica” (A20); e para (A7):

Precisamos formar mais professores de Matemática com essa visão de uso das tecnologias, pois nas nossas escolas, existem muitos computadores e os nossos alunos estão bem envolvidos com estes recursos, e a aprendizagem pode sim, com certeza, se através do computador ou de outros recursos tecnológicos. 
As contribuições de cada sujeito envolvido fizeram emergir uma participação ativa e colaborativa que suscitou dos alunos, na trajetória durante o curso, uma reflexão sobre a formação do professor nesses ambientes, permitindo sustentar que é possível ensinar e aprender Matemática nos MDV3D, desde que se articule a teoria e a prática para suas intervenções. Com isso, construíram espaços de reflexões no Open Sim (FIGURA 4) das diversas maneiras com que cada aluno manipulava e interferia nas mensagens, na realização e postagem dos desafios propostos, movimentando ideias de uma educação arquitetada na utilização de um MDV3D.

Figura 4 - Diálogo no chat do Open Sim entre avatares

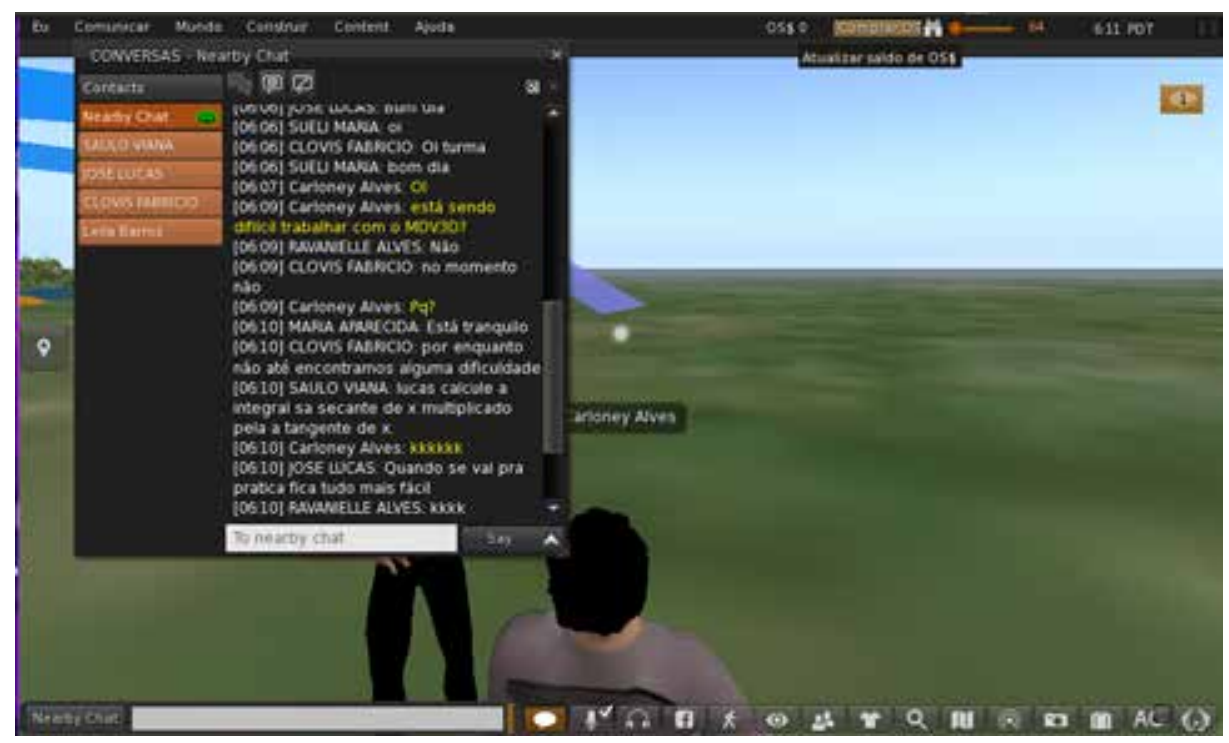

Fonte: Open Sim/UFAL (2015).

Percebemos no grupo de alunos do curso que a busca constante de informações sobre o uso das interfaces propostas precisava ser ampliado, para que se obtivesse êxito nas contribuições e acompanhamentos dos conteúdos apresentados durante o curso, que precisam refletir sobre o seu papel como aluno virtual (PALLOF; PRATT, 2004), propondo experiências de aprendizagem que solucionem os desafios da sociedade contemporânea.

A partir das ferramentas de construção no Open Sim, utilizando os MDV3D na formação do professor, planejamos espaços que contemplarão os momentos formativos e estabelecidos para tal fim, como, por exemplo, a biblioteca (FIGURA 5), ambiente construído para leitura e consulta aos materiais disponibilizados e outros espaços também foram criados para que permitissem ao aluno a leitura de trabalhos já apresentados em eventos nacionais e internacionais. 
Figura 5 - Biblioteca no MDV3D e Exposição de pôsteres sobre Tecnologias e Educação Matemática
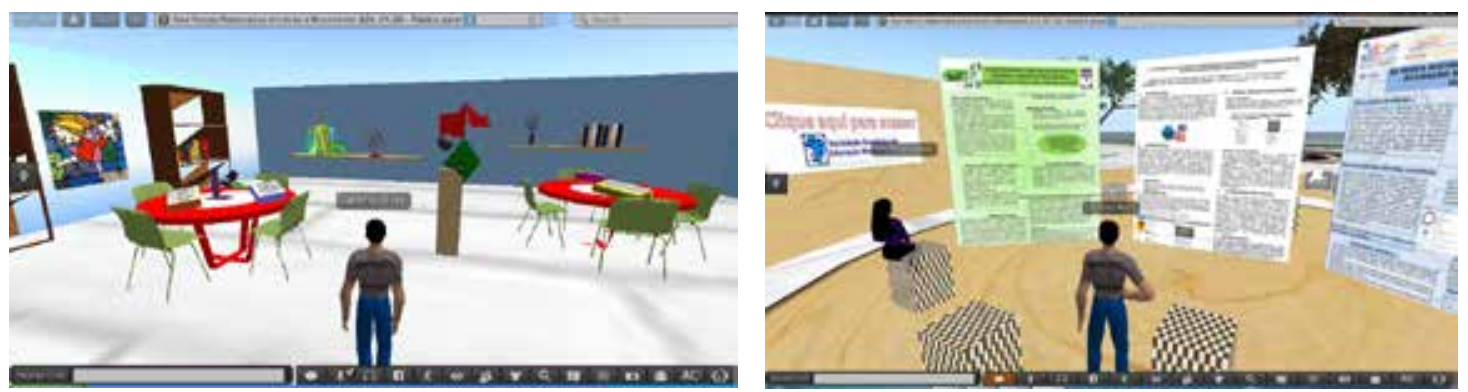

Fonte: Open Sim/UFAL (2015).

Outros espaços também foram criados para que permitissem ao aluno a leitura de trabalhos já apresentados em eventos nacionais e internacionais, identificando temáticas que gerem sentidos e significados para vivências necessárias a uma construção e/ou reconstrução dos eixos conceituais da Matemática, considerando, como caminhos das ações formativas.

Consideramos válidos todos os espaços construídos e integrados às inovações tecnológicas que os MDV3D possibilitam, compreendendo melhor como, quando e por que as tecnologias digitais podem contribuir no aprendizado e no desenvolvimento profissional do professor de Matemática, ampliando a sua utilização e apropriação, pedagogicamente fundamentado, em benefícios para a qualidade do ensino, da formação para o trabalho com estes ambientes e da compreensão crítica dos problemas de nosso tempo.

Constatamos, a partir das observações no Open Sim, que a navegabilidade dos alunos nos MDV3D, ao participarem de cada encontro planejado, foi favorável, a partir do momento que buscavam interagir com professor de forma que a utilização de cada interface apresentada para o grupo contribuísse para o processo de construção do conhecimento, com atividades e recursos dinâmicos que se encaixassem no espaço de integração do seu saber.

Para o manuseio de cada interface foi preciso uma orientação clara e objetiva da sua utilização (FIGURA 6), para que os alunos não sentissem dificuldades, ou quando sentissem, fossem orientados pelo professor, incentivando-os a perguntar, dialogar com os colegas, trocar informações que servissem para integrar ao contexto pessoal e coletivo, dentro de cada realidade. 
Figura 6 - Orientação sobre o Open Sim

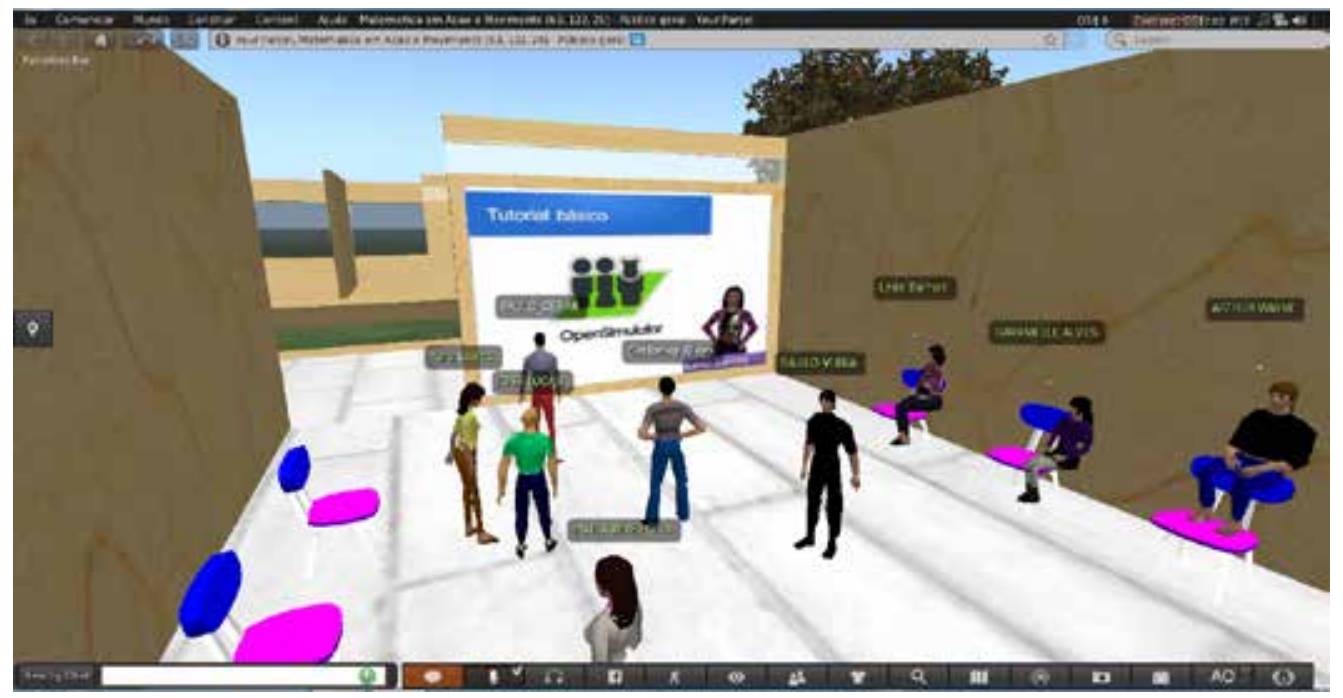

Fonte: Open Sim/UFAL (2015).

Os alunos buscaram identificar elementos que pudessem colaborar para uma melhor prática no Open Sim a partir das contribuições do professor em cada momento do curso. A possibilidade de comunicação síncrona e assíncrona no ambiente foi um aspecto muito bem destacado pelo grupo, que ressaltou a dinâmica de usabilidade das interfaces disponíveis no Open Sim.

Para aumentar a participação, a interação e uma melhor utilização das interfaces disponíveis no Open Sim entre professor e alunos, os alunos sugerem para o professor aspectos importantes que contribuem no processo de aprendizagem, mediante a troca constante de ideias e informações do curso: "Dedicar um maior tempo na participação na plataforma, para que todos possam dialogar com mais envolvimento" (A4), "Os horários estabelecidos nos encontros online, possam ser não só para estudos sobre uma temática proposta, mas também tirar dúvidas e reforçar conteúdos já estudados e que apresentamos uma certa dificuldade" (A7).

E,

Percebo que apesar de se tratar de um MDV3D, as pessoas possuem ainda numa certa timidez para participar das atividades propostas. Pois, quando há uma participação, ela é feita de forma mecânica, apenas para constar que houve participação. Tem que haver uma participação de forma natural e que isso deve ser feito através do estímulo do professor. (A9).

Já, continuando: “Na organização em relação à postagem das atividades e à postagem dos resultados de cada avaliação feita na aula anterior" (A14) e "Que além de textos disponibilizados no 
ambiente, fosse possível gravar videoaulas de minutos de duração para cada assunto. Isso facilitaria e muito nosso estudo" (A19).

Evidenciadas as resoluções de cada desafio proposto, os avatares explicitaram como foram resolvidas tais questões (FIGURA 7), confirmando a potencialidade das interfaces do ambiente, ampliando seus conhecimentos tanto do conteúdo envolvido como da dinâmica de funcionamento do Open Sim, tornando-a uma prática pedagógica de discussão, socialização e intervenções entre professor e alunos, na busca da sistematização das ideias e das contribuições dos sujeitos, individual e coletivamente.

Figura 7 - Avatares disponibilizando suas estratégias de resoluções
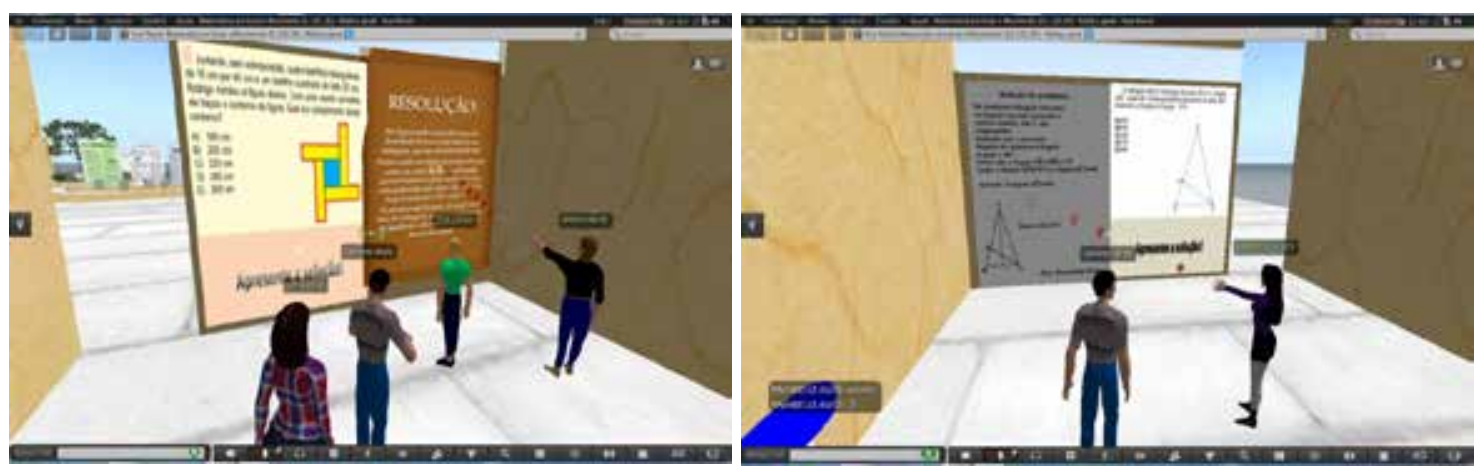

Fonte: Open Sim/UFAL (2015).

Constatou-se que não basta disponibilizar um material didático e interfaces no ambiente para que sejam executadas pelos alunos; é preciso que haja engajamento por parte de todos os envolvidos no processo, para eles venham a desempenhar o seu papel de aluno virtual, atendendo aos requisitos que a sociedade contemporânea exige e adequando-se às mudanças e transformações tecnológicas.

Ante a realidade vivenciada pelos alunos na imersão ao ambiente construído para o curso de extensão, constatou-se que algumas dificuldades de utilização dos MDV3D foram apresentadas, como, por exemplo, dificuldade de acesso ao ambiente, o manuseio nas interfaces, poucas interações mediante os textos disponibilizados e uma autonomia ainda limitada na busca constante do seu próprio conhecimento.

Constatou-se a falta do desenvolvimento de práticas pedagógicas interdisciplinares por meio do Open Sim, pois nesta perspectiva não houve interação com outras disciplinas, como revelam as falas de alguns alunos: "Não considero que na UFAL se trabalhe nessa perspectiva, pois cada professor trabalha sozinho, cada um fazendo o seu; é o professor e os alunos, não há uma interação com outras disciplinas, nem o planejamento se faz juntos. Cada qual organiza seu material. (A4)”. 
Ainda,

Apesar de na plataforma possibilitar espaços para se promover esta interação inter ou transdisciplinar, os compromissos de cada sujeito envolvido em utilizar a plataforma era desenvolver conteúdo e atividades que promovessem o desenvolvimento de sua disciplina. Esta interação, quando efetuada, ocorreu muito mais em razão da experiência do professor em efetuar essas conexões por iniciativa própria do que por um compromisso oficial de interagir com alunos em razão de desenvolver conexões interdisciplinares. Assim a dificuldade é muito mais de natureza administrativa na prática acadêmica curricular (A3).

Também, "Não explorei devidamente as potencialidades e possibilidades que este ambiente nos oferece, mas fico muito feliz com a interação e participação de todos. Fiz o básico” (A11).

Os alunos revelaram que a dificuldade de utilização do Open Sim não estava nas suas interfaces e sim na compreensão de como seriam disponibilizados os recursos do MDV3D para as aulas de Matemática, até porque nunca tinham visto algo parecido ou desse tipo no planejamento constante de um professor, devido à falta de formação e/ou orientações no seu processo formativo, visto que tais encaminhamentos poderiam ser dados para melhores intervenções e possibilidades de práticas nesta área tão complexa, que é a Matemática, como é considerada.

Dificuldades, sejam elas de compreensão da dinâmica do funcionamento do ambiente, seja pela falta de domínio com suas interfaces, problemas como acesso à internet ou ajustes nos seus horários para garantir uma efetiva participação e interação, foram superadas, pois cada sujeito participante do curso de extensão buscou romper com suas limitações e criar um espaço para o exercício da autonomia nos MDV3D, tornando como um momento significativo para a sua formação, compreendendo que estes espaços podem propiciar práticas pedagógicas que gerem um fluxo de ideias, compartilhamento de informações para a maturação e crescimento das suas capacidades tanto individuais quanto coletivas de construir conhecimentos.

No ambiente Open Sim, uma das vantagens da sua configuração é a possibilidade de as ferramentas de construção estarem na página principal, pois nessa janela é possível criar objetos, importar, exportar, modelar, dentre outras execuções e, conforme o planejamento do professor, podem-se agregar outros recursos e propor estratégias didáticas que possibilitam melhores práticas nos MDV3D.

Como sugestão, em um ambiente 3D imersivo planejado, é pertinente organizar o espaço numa arquitetura pedagógica com uma breve saudação inicial da equipe, dando boas vindas ao grupo; que disponibilize, em cada sala de aula construída, atividades interativas que possibilitem uma busca de novos conhecimentos; com um local para anúncios importantes, notícias, dúvidas, sugestões e quadro de avisos; com um espaço comunitário para troca de experiências e diálogos entre os avatares; com banners que apresentem resultados de pesquisas como estímulo para todos; com um ambiente para acesso a outros canais de informações; com a arena suspensa para a exposição de aulas ou apresentações de trabalhos; com a experimentoteca para que os avatares possam criar seus objetos e disponibilizá-los num espaço comum para todos.

Foi possível, também, a realização de eventos dentro do ambiente, tanto que organizamos o I 
Workshop MDV3D na Educação Matemática com os sujeitos envolvidos no curso, possibilitando que eles apresentassem trabalhos ou projetos de intervenção na área de Matemática, com o objetivo de socialização das atividades desenvolvidas por eles em suas salas de aula.

Cada avatar elaborou o seu pôster e o disponibilizou no espaço reservado para as apresentações no I Workshop MDV3D na Educação Matemática, que em seguida foi apresentado para os avatares imersos no Open Sim (FIGURA 8).

Figura 8 - I Workshop MDV3D na Educação Matemática

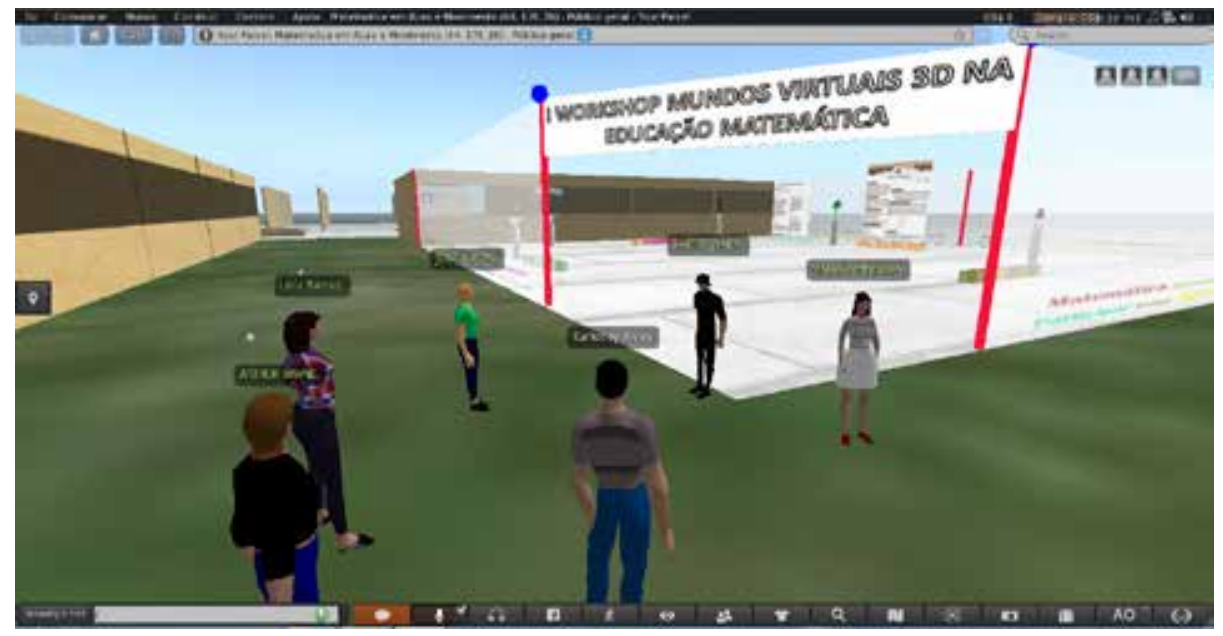

Fonte: Open Sim/UFAL (2015).

Sugerimos dividir estes espaços para cada temática planejada, disponibilizando todo o material didático preparado para o curso, sendo autoexplicativo no desenvolvimento da atividade que será exigida e quanto ao local em que será postada. Do ponto de vista organizacional, é viável apresentar o material que será trabalhado num mural informativo, facilitando o entendimento da dinâmica do curso para favorecer os processos de ensino e de aprendizagem nas aulas de Matemática.

Ao final do curso de extensão tivemos a oportunidade de avaliar a nossa trajetória, tecendo comentários sobre as contribuições e as potencialidades do Open Sim para a sua formação inicial e continuada, a partir das estratégias didáticas escolhidas para o desenvolvimento do curso (QUADRO 2), bem como as intenções e perspectivas futuras para se trabalhar com este ambiente nas aulas de Matemática, os pontos positivos e negativos e as sugestões para trabalhos futuros. 
Quadro 2 - Síntese das estratégias didáticas entre pesquisador e alunos

\begin{tabular}{|c|c|}
\hline Pesquisador & Alunos \\
\hline Atividades de resolução de problemas & $\begin{array}{l}\text { Resolveram os problemas através de } \\
\text { desenhos, imagens, escrita, algoritmo } \\
\text { matemático com os recursos disponíveis no } \\
\text { Open Sim. }\end{array}$ \\
\hline $\begin{array}{c}\text { Mediação das TDIC no ensino de } \\
\text { Matemática }\end{array}$ & $\begin{array}{l}\text { Construíram objetos 3D no Open Sim, } \\
\text { disponibilizaram imagens das resoluções } \\
\text { dos desafios propostos, utilizaram as } \\
\text { ferramentas de construção disponibilizadas } \\
\text { no ambiente, elaboraram pôsteres em } \\
\text { formato digital para postagem no espaço } \\
\text { reservado para tal fim. }\end{array}$ \\
\hline $\begin{array}{c}\text { Desafios de raciocínio lógico e jogos } \\
\text { matemáticos }\end{array}$ & $\begin{array}{l}\text { Interagiram com os demais avatares para o } \\
\text { compartilhamento de informações a partir do } \\
\text { chat e das mensagens enviadas, acessaram } \\
\text { os desafios através da decodificação do QR } \\
\text { com o aplicativo baixado em seus celulares, } \\
\text { exploraram os jogos matemáticos a partir de } \\
\text { simulações disponibilizadas no Open Sim e } \\
\text { interagiram com os colegas em encontros } \\
\text { agendados. }\end{array}$ \\
\hline
\end{tabular}

Fonte: Os autores (2015).

Necessitamos de olhares que, considerando o contexto dos MDV3D no ensino de Matemática, proporcionem estilos de compreensão, processamento e análises em torno desses ambientes como estratégias didáticas, não apenas para a manipulação de conteúdos e leituras exigidas, mas para compartilhamento de ideias e obtenção de conhecimentos, de acordo com suas necessidades, visando suas condições intelectuais ou interesses específicos. 


\section{CONSIDERAÇÕES FINAIS}

A imersão nos MDV3D na sociedade contemporânea vem crescendo nos últimos anos e pode contribuir para o contexto educacional, sendo possível encontrar soluções e justificativas para o melhor uso desses ambientes, adequando-os ao seu público-alvo e ao domínio do conhecimento.

Investigamos estratégias didáticas nos processos de ensino e de aprendizagem em Matemática nos MDV3D com um olhar voltado para as contribuições e as potencialidades destes ambientes, este estudo trouxe contribuições para a área de tecnologias digitais na formação de professores e Educação Matemática, pois por meio desses espaços é possível sistematizar o conhecimento matemático entre professor e alunos, a partir das interfaces disponibilizadas no ambiente, tais como: sons, imagens, textos e vídeos.

Da convivência durante três meses com os sujeitos da pesquisa, constatamos o desejo para uma melhor prática na utilização do MDV3D no curso, pelo fato de os alunos estarem à disposição para um acompanhamento sistemático e uma formação adequada, baseada no apoio, no diálogo e na colaboração. Neste período, verificamos que os limites dos sujeitos envolvidos em relação à utilização do MDV3D estão intrinsecamente relacionados com a falta de formação e de conhecimento das interfaces para uso no curso.

Nessa investigação percebemos que os alunos, no âmbito de um curso inicialmente presencial e em seguida on-line, por meio do Open Sim, podem conviver cada vez mais de perto com as potencialidades desses ambientes. Em contrapartida, ainda há uma desatualização tecnológica por parte dos envolvidos para lidar com essa questão. As formações para lidar com esse tipo de ambiente ainda não são suficientes para fazer com que professor e alunos se sintam à vontade para navegar, interagir e proporcionar práticas inovadoras no processo de ensino e de aprendizagem nas aulas de Matemática.

Um mergulho no universo desses sujeitos a partir da utilização das interfaces do Open sim evidencia o entendimento de que é urgente repensar as práticas pedagógicas nesses ambientes, buscando ajustá-las às necessidades e aos objetivos de cada sujeito, selecionando interfaces e serviços da internet que sejam adequados para determinados propósitos.

A experiência de analisar estratégias didáticas na formação do professor de Matemática com o apoio dos MDV3D levou à compreensão de que estes ambientes revelam potencialidades e contribuições que apontam para uma mudança premente dos sistemas educativos, a fim de que se instituam novas relações entre o saber pedagógico e o saber científico. 


\section{REFERENCIAS}

ALMEIDA, M. E.; SILVA, M. da G. M. da. Currículo, tecnologia e cultura digital: espaços e tempos de web currículo. Revista E-curriculum, São Paulo, v. 7, n. 1, p. 1-19, abr. 2011. Disponível em: http:// revistas.pucsp.br/index.php/curriculum/article/viewFile/5676/4002. Acesso em: 18 dez. 2014.

BACKES, L. A configuração do espaço de convivência digital virtual: a cultura emergente no processo de formação do educador. Tese (Doutorado em Educação) - Universidade do Vale do Rio dos Sinos, São Leopoldo; Université Lumière Lyon 2, Lyon, 2011.

BACKES, L. Metodologias, práticas e mediação pedagógica em metaverso. In: SCHLEMMER E. et al. Comunidades de aprendizagem e de prática em metaverso. São Paulo: Cortez, 2012. p. 179-201.

BEHAR, P. A.; MARIA, S. A. Competências docentes para o uso de metaversos na educação a distância. In: BEHAR, P. A.; MARIA, S. A. (Org.). Competências em educação a distância. Porto Alegre: Penso, 2013. p. 195-210.

HAYDT, R. C. Curso de didática geral. 8. ed. São Paulo: Ática, 2006.

LEMOS, A. L. Anjos interativos e retribalização do mundo: sobre interatividade e interfaces digitais, 1997. Disponivel em: http://www.facom.ufba.br/ciberpesquisa/lemos/ interativa.pdf. Acesso em: 18 maio 2019.

MARTINS, J. S. Situações práticas de ensino e aprendizagem significativa. Campinas: Autores Associados, 2009.

MORAES, R.; GALIAZZI, M. do C. Análise textual discursiva. 2. ed. rev. ljuí-RS: Ed. Unijuí, 2013.

PALLOF, R. M.; PRATT, K. 0 aluno virtual: um guia para trabalhar com estudantes online. Porto Alegre: Artmed, 2004.

PEREIRA, Alice T. (Org.). Ambientes virtuais de aprendizagem em diferentes contextos. Rio de Janeiro: Ciência Moderna, 2007.

SCHLEMMER, E. Metaversos: novos espaços para construção do conhecimento. Revista Diálogo Educacional, Curitiba, v. 8, n. 24, p. 519-532, maio/ago. 2008.

SCHLEMMER, E. Origens e fundamentos da tecnologia de metaverso. In: SCHLEMMER, E. et. al. Comunidades de aprendizagem e de prática em metaverso. São Paulo: Cortez, 2012. p. 61-126. 
SILVA, O. S. Tessituras (hiper) textuais: leitura e escrita nos cenários digitais. Salvador: Quarteto, 2008.

VALENTE, J. A. A espiral da aprendizagem e as tecnologias da informação e comunicação: repensando conceitos. In: JOLY, M. C. (Org). A tecnologia no ensino: implicações para a aprendizagem. São Paulo: Casa do Psicólogo, 2002. p. 15-37. 
1 Doutor em Educação - UFAL; Professor Adjunto do Curso de Pedagogia na área de Saberes e Metodologias do Ensino da Matemática da Universidade Federal de Alagoas - UFAL; Professor vinculado ao Programa de Pós-Graduação em Ensino de Ciências e Matemática (PPGECIM) - UFAL; Líder do Grupo de Pesquisa em Tecnologias Educativas e Práticas Pedagógicas em Educação Matemática (GEPTPEM).

E-mail: carloneyalves@gmail.com

2 Doutor em Educação - PUC/SP; Professor Titular da Universidade Federal de Alagoas - UFAL; Professor vinculado ao Programa de Pós-Graduação em Educação (PPGE) - UFAL; Líder do Grupo de Pesquisa Tecnologias da Informação e Comunicação na Formação de Professores Presencial e Online (TICFORPROD).

E-mail: luispaulomercado@gmail.com

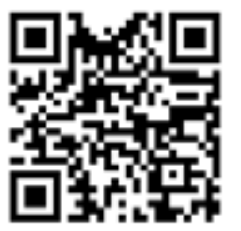

A autenticidade desse artigo pode ser conferida no site https://periodicos. set.edu.br

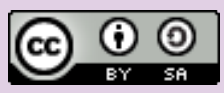

Este artigo é licenciado na modalidade acesso abertosob a Atribuição-Compartilhalgual CC BY-SA

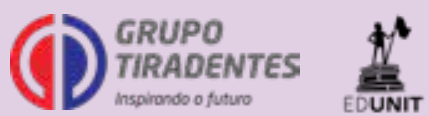

